\title{
On non-marginal cost-benefit analysis
}

\author{
Simon Dietz and Cameron Hepburn
}

March 2010

Centre for Climate Change Economics and Policy

Working Paper No. 20

Grantham Research Institute on Climate Change and the Environment

Working Paper No. 18 
The Centre for Climate Change Economics and Policy (CCCEP) was established by the University of Leeds and the London School of Economics and Political Science in 2008 to advance public and private action on climate change through innovative, rigorous research. The Centre is funded by the UK Economic and Social Research Council and has five inter-linked research programmes:

1. Developing climate science and economics

2. Climate change governance for a new global deal

3. Adaptation to climate change and human development

4. Governments, markets and climate change mitigation

5. The Munich Re Programme - Evaluating the economics of climate risks and opportunities in the insurance sector

More information about the Centre for Climate Change Economics and Policy can be found at: http://www.cccep.ac.uk.

The Grantham Research Institute on Climate Change and the Environment was established by the London School of Economics and Political Science in 2008 to bring together international expertise on economics, finance, geography, the environment, international development and political economy to create a worldleading centre for policy-relevant research and training in climate change and the environment. The Institute is funded by the Grantham Foundation for the Protection of the Environment, and has five research programmes:

1. Use of climate science in decision-making

2. Mitigation of climate change (including the roles of carbon markets and lowcarbon technologies)

3. Impacts of, and adaptation to, climate change, and its effects on development

4. Governance of climate change

5. Management of forests and ecosystems

More information about the Grantham Research Institute on Climate Change and the Environment can be found at: http://www.Ise.ac.uk/grantham.

This working paper is intended to stimulate discussion within the research community and among users of research, and its content may have been submitted for publication in academic journals. It has been reviewed by at least one internal referee before publication. The views expressed in this paper represent those of the author(s) and do not necessarily represent those of the host institutions or funders. 


\title{
ON NON-MARGINAL COST-BENEFIT ANALYSIS
}

\author{
Simon Dietz ${ }^{\dagger *}$ And Cameron Hepburn ${ }^{\dagger \dagger}$
}

11 March 2010

Running title: On non-marginal cost-benefit analysis.

JEL Classification Numbers: H43, D61, Q54.

Keywords: Cost-benefit analysis, non-marginal, project appraisal, discount rate, infrastructure investment, climate change, hydropower dam.

\footnotetext{
${ }^{\dagger}$ Grantham Research Institute on Climate Change and the Environment, London School of Economics and Political Science.

*Department of Geography and Environment, London School of Economics and Political Science.

${ }^{\ddagger}$ Smith School of Enterprise and the Environment, and New College, University of Oxford.

We thank David Anthoff, Partha Dasgupta, Francis Dennig, Christian Gollier, Chris Hope, John Quah, Robert Ritz, Sjak Smulders, Nick Stern, participants at EAERE 2009, seminar participants at the Toulouse School of Economics and especially Antony Millner. We would also like to acknowledge the financial support of the Grantham Foundation for the Protection of the Environment, as well as the Centre for Climate Change Economics and Policy, which is funded by the UK's Economic and Social Research Council and by Munich Re. The usual disclaimer applies.

Email for correspondence: s.dietz@lse.ac.uk.

Telephone: +44 2079557589 .

Fax: +44 2071061241 .
} 


\title{
ON NON-MARGINAL COST-BENEFIT ANALYSIS
}

\begin{abstract}
Conventional cost-benefit analysis incorporates the normally reasonable assumption that the policy or project under examination is marginal in the sense that it will not significantly change relative prices. In particular, it is assumed that the policy or project does not change the underlying growth rate of the economy. However, these assumptions may be inappropriate in some important circumstances, such as large development projects in small economies, or large-scale infrastructure investment programmes. This paper develops the theory on the evaluation of non-marginal policies and projects, with an empirical application to the mitigation of global climate change. We examine the conditions under which evaluation of a non-marginal project using marginal methods may be both qualitatively and quantitatively wrong, and explore the magnitude of the potential error using a commonly employed integrated assessment model of climate change.
\end{abstract}

JEL Classification Numbers: H43, D61, Q54.

Keywords: Cost-benefit analysis, non-marginal, project appraisal, discount rate, infrastructure investment, climate change, hydropower dam. 


\section{Introduction}

Cost-benefit analysis (CBA) of major policies, programmes and projects is becoming more widely used to inform and improve decisions (Hahn and Tetlock, 2008). In the United States and the United Kingdom, for instance, there is now a legislative requirement to conduct CBA of significant new policies and policy reforms, while other countries and regional organisations such as the European Commission have made steps in the same direction (Pearce et al., 2006). In addition, there is a long tradition of CBA of major projects by the World Bank and other multilateral financial institutions.

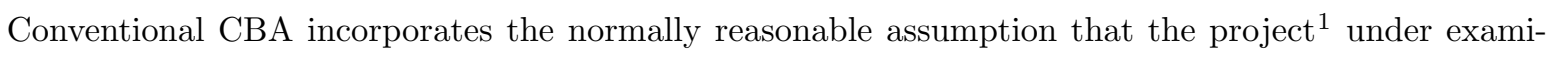
nation is marginal in the sense that it will not significantly change relative prices. While many projects clearly satisfy this condition, not all of them do, and indeed it is arguable that some of the most worthwhile projects are unlikely to be small in this sense (Hammond, 1990). Indeed, many projects are designed precisely to change relative prices in a non-marginal way.

A rare but important category of project not only changes relative prices, but also shifts the underlying growth rate of the relevant economy. Large development projects in small economies or large-scale infrastructure investment programmes may be explicitly intended to increase growth rates and change the development path of the economy. In a similar fashion, proposals to spend several per cent of global GDP on the deployment of "low-carbon" technologies, such as renewable energy, smart electricity grids and transport infrastructure, are explicitly intended to shift the growth path of global GDP, accounting for externalities, by avoiding climate change.

In their classic text on project appraisal, Dasgupta et al. (1972) largely focus on marginal, rather than non-marginal, projects. Nevertheless they do note that different considerations may apply to large projects:

we tacitly assumed that...the proposed project is "small", i.e. the "range" of the net benefits of the project is small compared with the size of aggregate consumption. [Where this assumption

\footnotetext{
${ }^{1}$ Henceforth will use the word "project" to denote any change in "business as usual", whether arising from a private-sector or government policy, programme or project.
} 
is untrue], it might seem plain that the EPV rule will not suffice then. One would like to know what rule should replace it. One would also like to know whether the evaluator would make serious errors if he stuck to the EPV rule in such cases. (p111)

While Dasgupta et al. (1972) briefly examine whether errors might occur, they do so with a simple back-of-the-envelope calculation involving a highly specific utility function $(u(c)=-10000 / c)$ and a project that results in a once-off cash flow. Surprisingly, it does not appear that a wider literature has developed to address their questions, ${ }^{2}$ even though it is not particularly difficult to think of examples where the project undertaken might have been large enough to shift the growth path of the economy. Dasgupta et al. (1972) give the Aswan dam in Egypt as a possible example of the time. In this paper we look at the contemporary example of the "Nam Theun II" hydroelectric power project in Laos, and examine more thoroughly a globally coordinated policy to abate greenhouse gas emissions.

In the case of climate change, many analyses have ignored the possibility that investing in emissions abatement could be non-marginal, at least in terms of how they conducted CBA. For example, Tol's (2005) review of the empirical literature shows that, of the 103 estimates of the shadow value of emissions abatement he considered, 62 ignored the possibility of a shift in the growth path, because they took a partial-equilibrium approach, in which the consumption discount rate (which depends on estimated future growth) was set irrespective of the size of future cash flows and their effect on the growth rate. That is to say, in these 62 cases the consumption discount rate was set exogenously. More generally, the tendency to base views about the appropriate consumption discount rate for use in evaluation of climate change mitigation on exogenous expectations of future growth is easy to observe in recent debates (e.g. Byatt et al., 2006). At the same time, however, we should also highlight the 41 estimates from Tol's review that did take into account possible shifts in the growth path, by virtue of evaluating the project in a general equilibrium framework, in which the consumption discount rate was endogenous. These include Nordhaus' well-known studies (1994, 2008; Nordhaus and Boyer, 2000), and more recently the analysis of Stern (2007).

\footnotetext{
${ }^{2}$ For instance, Hammond (1990) only makes limited reference to non-marginal projects, and only considers the impact of changes to relative prices rather than the economic growth rate. Similarly, there is no treatment of non-marginal projects in recent texts in public economics, such as Myles (1995), or project appraisal, such as Mishan and Quah (2007).
} 
Hence this paper focuses on the standard short-cuts of project appraisal, rather than any shortcomings of the general equilibrium model. It attempts to address the question of whether "serious errors" could be made by evaluating non-marginal projects with conventional CBA, which uses discounted cash flow (DCF) analysis to determine net present value (NPV). Section 2 reviews the relevant public economic theory and presents the result that if a project is evaluated to have positive NPV, then it is also welfareimproving, provided that the project is marginal. A Taylor-series expansion provides an expression of the error involved in evaluating non-marginal projects, and comparative statics, including the impact of growing population, are examined. Section 3 applies this theory to investment in global climatechange mitigation, using the integrated assessment model employed by Stern (2007) in his review of the economics of climate change. Using this model, we examine the conditions under which evaluation of a non-marginal project using marginal methods may be both qualitatively and quantitatively wrong, and explore the magnitude of the potential error. Section 4 reports the results of this analysis, the most significant of which is that it is possible for marginal CBA to provide qualitatively and quantitatively incorrect guidance, because impacts on the underlying economic growth path are ignored. Section 5 concludes.

\section{Theory}

\subsection{Marginal CBA of a non-marginal project}

A core proposition of CBA is that if DCF analysis shows that a project has positive NPV, then the project is welfare-improving (see proposition 1). Define $\Delta_{t}$ as the cash flows at time $t$ from the project, which are discounted at consumption discount rate $\rho_{t}$ to yield project NPV. Define $c_{t}$ as business-as-usual consumption providing utility $u\left(c_{t}\right)$, with $u^{\prime}\left(c_{t}\right)>0$ and $u^{\prime \prime}\left(c_{t}\right)<0$, with corresponding utility discount rate $\delta_{t}$. Proposition 1 sets out the core justification for DCF analysis in project appraisal.

Proposition 1. Provided $u\left(c_{t}+\Delta_{t}\right)=u\left(c_{t}\right)+u^{\prime}\left(c_{t}\right) \Delta_{t}$, then

$$
\sum_{t=0}^{\tau} \Delta_{t}\left(1+\rho_{t}\right)^{-t}>0 \Longrightarrow \sum_{t=0}^{\tau}\left[u\left(c_{t}+\Delta_{t}\right)-u\left(c_{t}\right)\right]\left(1+\delta_{t}\right)^{-t}>0
$$


Proof. Apply the Euler equation to substitute for the consumption discount factor $\left(1+\rho_{t}\right)^{-t}$ on the left-hand side of Eq. (1). Further, provided the first-order Taylor approximation of the utility function around $c_{t}$ is exact, so that $u\left(c_{t}+\Delta_{t}\right)=u\left(c_{t}\right)+u^{\prime}\left(c_{t}\right) \Delta_{t}$, it follows that:

$$
\sum_{t=0}^{\tau} \Delta_{t}\left(1+\rho_{t}\right)^{-t}=\sum_{t=0}^{\tau} \Delta_{t} \frac{u^{\prime}\left(c_{t}\right)}{u^{\prime}\left(c_{0}\right)}\left(1+\delta_{t}\right)^{-t}=\frac{1}{u^{\prime}\left(c_{0}\right)} \sum_{t=0}^{\tau}\left[u\left(c_{t}+\Delta_{t}\right)-u\left(c_{t}\right)\right]\left(1+\delta_{t}\right)^{-t}
$$

As $u^{\prime}\left(c_{0}\right)>0$, it follows from Eq. (2) that the implication in Eq. (1) holds.

Proposition 1 states that for marginal projects (where the first-order Taylor approximation holds), if a project has positive NPV, it is also welfare-increasing (Little and Mirrlees, 1974). What if the first-order approximation does not hold? The full Taylor series expansion of utility around consumption level $c_{t}$ is:

$$
u\left(c_{t}+\Delta_{t}\right)=u\left(c_{t}\right)+u^{\prime}\left(c_{t}\right) \Delta_{t}+\Omega
$$

where $\Omega$ is the error in the first-order approximation, which may be given by the expression for Cauchy's remainder:

$$
\Omega=u^{\prime \prime}\left(c_{t}\right) \frac{\Delta_{t}^{2}}{2 !}+u^{\prime \prime \prime}\left(c_{t}\right) \frac{\Delta_{t}^{3}}{3 !}+\ldots=\sum_{j=2}^{\infty} u^{j}\left(c_{t}\right) \frac{\Delta_{t}^{j}}{j !}
$$

For an isoelastic utility function, $u\left(c_{t}\right)=c_{t}^{1-\eta} /(1-\eta)$, with elasticity of marginal utility $\eta$, this error is:

$$
\Omega=-\eta c_{t}^{-\eta-1} \frac{\Delta_{t}^{2}}{2 !}+\eta(\eta+1) c_{t}^{-\eta-2} \frac{\Delta_{t}^{3}}{3 !}+\ldots=\sum_{j=2}^{\infty}\left[\prod_{i=2}^{j}(\eta+i-2)\right](-1)^{j+1} c_{t}^{1-\eta-j} \frac{\Delta_{t}^{j}}{j !}
$$

For linear utility, $\eta=0$, the error $\Omega=0$ and the first-order Taylor expansion is exact. At the other extreme, as $\eta \rightarrow \infty$, it is also true that $\Omega=0$ provided $c_{t}>1$. In other words, when the elasticity of marginal utility, $\eta$, takes on values at the extreme ends of the range $[0, \infty)$, the error in using conventional CBA is likely to be limited, even for a non-marginal project.

However, when $\eta$ has an intermediate value, the error involved in evaluating a non-marginal project could be substantial. Unfortunately, reasonable values of $\eta$ are intermediate values; $\eta$ is generally taken to be in $[0.5,10]$ (Stern, 1977), and often values of $[1,4]$ are seen as being appropriate (Atkinson, 1970; Johansson-Stenman et al., 2002). For instance, it is often convenient and not unreasonable to assume logarithmic utility, with $\eta=1$, in public economic analysis. The review of climate-change economics by Stern (2007) did just that. Following the Stern Review, several economists (Weitzman, 2007; Dasgupta, 2007) argued that more suitable values of $\eta$ were in the range $[2,4]$. On the other hand, Atkinson and 
Brandolini (2008) point to evidence from the literature on inequality, which supports values in the range $[0.125,2]$, and Layard et al. (2008), in analysing data on subjective happiness, put $\eta$ at just over unity. In any case, very few economists would argue that a central estimate for $\eta$ is much below 0.5 or much above 5 .

With logarithmic utility, the error in applying marginal DCF to a non-marginal project is:

$$
\Omega=-\frac{1}{2}\left(\frac{\Delta_{t}}{c_{t}}\right)^{2}+\frac{1}{3}\left(\frac{\Delta_{t}}{c_{t}}\right)^{3}-\frac{1}{4}\left(\frac{\Delta_{t}}{c_{t}}\right)^{4}+\ldots=\sum_{j=2}^{\infty}-\frac{\Delta_{t}^{j}}{j\left(-c_{t}\right)^{j}}
$$

How significant could this error be? Consider a once-off, non-marginal positive cash flow at time $t$ of $\Delta_{t}$. The true increase in utility derived from this cash flow is $\log \left(c_{t}+\Delta_{t}\right)-\log \left(c_{t}\right)$. The first-order approximation (see Eq. (3)) is $\Delta_{t} / c_{t}$, and the error in that approximation is given by Eq. (6). Suppose the cash flow $\Delta_{t}$ from the project is positive but much smaller than business-as-usual consumption, such that $0<\left(\Delta_{t} / c_{t}\right)<<1$, but is nevertheless large enough to be non-marginal. Then the error can itself be approximated by the Lagrange remainder, which here is the same as the second-order term in Eq. (6), namely: $-\frac{1}{2}\left(\Delta_{t} / c_{t}\right)^{2}$. The increase in utility is therefore roughly overestimated by the fraction:

$$
\frac{\frac{1}{2}\left(\Delta_{t} / c_{t}\right)^{2}}{\log \left(c_{t}+\Delta_{t}\right)-\log \left(c_{t}\right)} \approx \frac{\frac{1}{2}\left(\Delta_{t} / c_{t}\right)^{2}}{\Delta_{t} / c_{t}}=\frac{1}{2}\left(\frac{\Delta_{t}}{c_{t}}\right)
$$

For instance, if a project delivers a once-off benefit $\left(\Delta_{t} / c_{t}\right)$ of $10 \%$ of current consumption, then conventional DCF analysis will overestimate the actual increase in utility by approximately $5 \%$, simply because the marginal evaluation ignores curvature in the utility function. A $5 \%$ overestimate of benefits could make some welfare-reducing projects appear welfare-enhancing, and vice versa for a $5 \%$ underestimate. Of course, there are not many projects that involve increasing business-as-usual consumption by $10 \%$ in one year. However, for projects with moderately high cash flows over several decades or more, even annual errors of just a percentage point or two might add up to a significant overall error, and potentially an incorrect policy prescription.

Large infrastructure projects in small economies could be non-marginal. An example is the "Nam Theun II" hydroelectric power project in Laos, construction on which commenced in 2005 and is due to finish in 2010. According to the CBA of the World Bank (World Bank and MIGA, 2005), which has provided loans and guarantees for the project, the net benefits of the dam range from around -\$US 
Table 1: Net benefits relative to consumption for "Nam Theun II" dam in Laos

\begin{tabular}{cccc}
\hline \hline Year & Net benefits (\$US million) & Consumption (\$US million) & Net benefits / consumption \\
\hline 1 & -74 & 2100 & $-3.5 \%$ \\
2 & -170 & 2220 & $-7.7 \%$ \\
3 & -210 & 2360 & $-8.9 \%$ \\
4 & -240 & 2500 & $-9.6 \%$ \\
5 & -200 & 2650 & $-7.5 \%$ \\
6 & -110 & 2810 & $-3.9 \%$ \\
7 & 240 & 2970 & $8.1 \%$ \\
8 & 240 & 3150 & $7.6 \%$ \\
9 & 250 & 3340 & $7.5 \%$ \\
10 & 240 & 3540 & $6.8 \%$ \\
\hline \hline
\end{tabular}

240 million during the construction phase to $\$$ US 250 million during its operation. To put these figures in context, current consumption in Laos is just over $\$ 2$ billion. Indeed, as Table 2.1 shows, if Laos' consumption is assumed to continue to grow at its average over the period 1998-2008 of around 6\% per annum, then $\left(\Delta_{t} / c_{t}\right)$ in the first ten years of the project's life ranges from $-9.5 \%$ to $8 \%$. If the project were to be evaluated using the marginal approach, as indeed it was in the World Bank CBA according to standard practice, errors of several percentage points per annum would not be implausible.

Climate change mitigation is another possible example. According to Stern (2007), for instance, global climate change mitigation might roughly yield the equivalent of a once-off cash flow of $5 \%-20 \%$ of global consumption. This is investigated in more detail in section 3.

\subsection{Non-marginal projects and population growth}

The foregoing analysis assumed constant population. Yet many large projects are conducted in economies with (sometimes rapid) population growth. As we will see, allowing for population growth with non-marginal projects can generate some counterintuitive results. Denote population at time $t$ as $n_{t}$, and the population growth rate as $g_{t}$ per period such that $n_{t}=n_{0}\left(1+g_{t}\right)^{t}$. Define a 'population-augmented 
discount factor' $\beta_{t}=\left(1+g_{t}\right)^{t}\left(1+\delta_{t}\right)^{-t}$, where $\beta_{0}=1$, to reflect utility discounting and population growth combined. Finally, assume that individuals have identical utility functions, $u\left(c_{t}\right)$. The utilitarian welfare increase, denoted $\Delta V$, generated by a project with per capita cash flows of $\Delta_{t}$ is given by:

$$
\Delta V=n_{0} \sum_{t=0}^{\tau} \beta_{t}\left[u\left(c_{t}+\Delta_{t}\right)-u\left(c_{t}\right)\right]
$$

Let $\pi$ denote the NPV per capita (in terms of consumption) corresponding to welfare increase $\Delta V$, such that $\pi$ is implicitly defined by the equation:

$$
\Delta V=n_{0}\left[u\left(c_{0}+\pi\right)-u\left(c_{0}\right)\right]
$$

Combining Eqs. (8) and (9) and incrementing the summation index implicitly defines $\pi$ as follows:

$$
u\left(c_{0}+\pi\right)+\sum_{t=1}^{\tau} \beta_{t} u\left(c_{t}\right)=\sum_{t=0}^{\tau} \beta_{t} u\left(c_{t}+\Delta_{t}\right)
$$

Assume that costs are incurred before benefits are accrued. To fix ideas, suppose there are two periods, $t=0,1$, where the project is represented by $\Delta_{0}<0<\Delta_{1}$. In this case, $\pi$ is implicitly defined by the equation

$$
u\left(c_{0}+\pi\right)+\beta_{1} u\left(c_{1}\right)=u\left(c_{0}+\Delta_{0}\right)+\beta_{1} u\left(c_{1}+\Delta_{1}\right)
$$

For a marginal project in a growing economy (so $c_{1}>c_{0}$ ), any increase in the concavity of the utility function - an increase in $\eta$ for an isoelastic utility function — reduces $\pi$. This is because increasing $\eta$ reduces the marginal utility of consumption in the period with high consumption $(t=1)$ relative to the period with low consumption $(t=0)$, and the benefits $\Delta_{1}$ are realised in the period of high consumption. In other words, provided there is positive consumption growth, $g$, the consumption discount rate $\rho=\delta+\eta g$ increases with $\eta$, so future benefits are discounted more heavily and $\pi$ is lower. ${ }^{3}$

However, if the project is non-marginal, and population is increasing, it is possible that increasing $\eta$ from zero can increase the project's $\pi$, as seen in Figure 1. Proposition 2 sets out two necessary conditions for this result.

\footnotetext{
${ }^{3}$ Note that we have abstracted here from questions of equity weighting and inequality aversion, discussed by Dasgupta (2007), by assuming that individuals are identical.
} 
Proposition 2. Suppose that $c_{0} \leq c_{1}$ and $\Delta_{0} \leq 0 \leq \Delta_{1}$. Necessary conditions for $\partial \pi / \partial \eta>0$ at $\eta=0$ are

$$
\begin{aligned}
\beta & >1 \text { and } \\
\Delta_{1} & >\frac{c_{1}-c_{0}-\Delta_{0}}{\beta_{1}-1}
\end{aligned}
$$

Proof. Implicitly differentiating Eq. (11) with respect to $\eta$, using the chain rule, and setting $\eta=0$ yields

$$
\left.\frac{\partial \pi}{\partial \eta}\right|_{\eta=0}=\left(c_{0}+\pi\right)\left[f\left(c_{0}+\pi\right)-f\left(c_{0}+\Delta_{0}\right)+\beta_{1}\left\{f\left(c_{1}\right)-f\left(c_{1}+\Delta_{1}\right)\right\}\right]
$$

where $f(x) \equiv x \ln x$. As $\left(c_{0}+\pi\right)>0$ for any plausible project, and as $\pi=\Delta_{0}+\beta_{1} \Delta_{1}$ at $\eta=0, \partial \pi / \partial \eta>0$ at $\eta=0$ requires

$$
\frac{f\left(c_{0}+\Delta_{0}+\beta_{1} \Delta_{1}\right)-f\left(c_{0}+\Delta_{0}\right)}{\beta_{1} \Delta_{1}}>\frac{f\left(c_{1}+\Delta_{1}\right)-f\left(c_{1}\right)}{\Delta_{1}}
$$

Denote $m(x, d)$ as the gradient of the chord from $(x, f(x))$ to $(x+d, f(x+d))$, such that $m(x, d)=$ $[f(x+d)-f(x)] / d$. We can reexpress the inequality in Eq. (15) as

$$
m\left(c_{0}+\Delta_{0}, \beta_{1} \Delta_{1}\right)>m\left(c_{1}, \Delta_{1}\right)
$$

To derive the necessary condition in Eq. (12), note that $m_{x}(x, d)>0$ and $m_{d}(x, d)>0$, as $f^{\prime \prime}>0$, and because $m_{d}(x, d)>0$, increasing $\beta_{1}$ increases $m\left(c_{0}+\Delta_{0}, \beta_{1} \Delta_{1}\right)$. Note that if $\beta_{1}=1$, then for the inequality in Eq. (16) to hold true would require $m\left(c_{0}+\Delta_{0}, \Delta_{1}\right)>m\left(c_{1}, \Delta_{1}\right)$, which would require $c_{0}+\Delta_{0}>c_{1}$ because $m_{x}(x, d)>0$. However, $c_{0}+\Delta_{0}<c_{1}$ as by assumption the economy is growing $\left(c_{1}>c_{0}\right)$ and the project is costly $\left(\Delta_{0}<0\right)$. As $\beta_{1}=1$ is inadequate and as $m_{d}(x, d)>0$, it follows that $\beta_{1}>1$ is a necessary condition for Eq. (16) to hold and hence for $\partial \pi / \partial \eta>0$ at $\eta=0$.

To derive the necessary condition in Eq. (13), compare a chord joining the point $\left(x_{1}, f\left(x_{1}\right)\right)$ to $(s, f(s))$ with a chord joining the point $\left(x_{2}, f\left(x_{2}\right)\right)$ to $(s, f(s))$ where $s>x_{2}>x_{1}$. Note that $m\left(x_{1}, s-x_{1}\right)<$ $m\left(x_{2}, s-x_{2}\right)$ because $f^{\prime \prime}>0$. Applying this, now suppose $s=c_{0}+\Delta_{0}+\beta_{1} \Delta_{1}=c_{1}+\Delta_{1}, x_{2}=c_{1}$ and $x_{1}=c_{0}+\Delta_{0}$. Then for the inequality in Eq. (16) to hold would require $c_{0}+\Delta_{0}>c_{1}$, because $m\left(x_{1}, s-x_{1}\right)<m\left(x_{2}, s-x_{2}\right)$. But as noted above, the opposite is true. Hence, because $m_{x}(x, d)>0$, $c_{0}+\Delta_{0}+\beta_{1} \Delta_{1}>c_{1}+\Delta_{1}$ is required, which implies $\Delta_{1}>\frac{c_{1}-c_{0}-\Delta_{0}}{\beta_{1}-1}$ is a necessary condition for Eq. (16) to hold and hence for $\partial \pi / \partial \eta>0$ at $\eta=0$. 
The intuition behind this result may be seen in three parts. First, when population growth is fast enough that $\beta_{1}>1$, project NPV per capita, $\pi$, can be extremely high. Second, in Eq. (11) the utility with the project $\Delta_{t}$ (on the right-hand side) is by definition equal to the utility without the project, but where initial consumption is increased by the project NPV per capita $\pi$ (on the left-hand side). If $\pi$ must be large for this equality to hold, then obviously $c_{0}+\pi$ is also large. Third, introducing concavity in the utility function (by increasing $\eta$ from 0 ) leads to a greater reduction in marginal utility in periods of relatively high consumption. When $\beta_{1}>1$ and $c_{0}+\pi$ is large, it is possible that for the equality in Eq. (11) to hold, $\pi$ must increase to offset the relative reduction in marginal utility of $c_{0}+\pi$ from increasing $\eta$ above zero. The relationship is not monotonic, however, and increases in $\eta$ above a certain level will have the expected effect of reducing $\pi$, because of reductions in the marginal utility of the project benefits, as seen in Figure 1.

In other words, it follows from proposition 2 that necessary conditions for the unusual relationship between project NPV and the elasticity of marginal utility, of the sort shown in Figure 1, are that population growth is fast enough that $\beta>1$, and that the project is sufficiently non-marginal in the sense that the benefits are large enough that $\Delta_{1}>\frac{c_{1}-c_{0}-\Delta_{0}}{\beta_{1}-1}$. Although it may seem surprising, precisely this increasing relationship between NPV and the elasticity of marginal utility is observed in some scenarios of the integrated assessment model of climate change discussed in the following section.

\section{[Insert Figure 1 (non-monotonic relationship between $\pi$ and $\eta$ ) about here.]}

\section{Application to an Integrated Assessment Model of Climate Change}

\subsection{Mitigation of Climate Change}

Consider a globally-coordinated investment project, with cash flows $\Delta_{t}$, which reduces emissions of carbon dioxide $\left(\mathrm{CO}_{2}\right)$ on a large scale over several decades. Let $c_{t}^{b}$ represent business-as-usual global consumption per capita when carbon emissions are uncontrolled, resulting in climate change that has a non-marginal cost, both through the cost of adapting to it (e.g. raising coastal defences) and through its residual impacts (e.g. coastal flooding). Let $c_{t}^{b}+\Delta_{t}$ represent consumption along a path where 
carbon emissions are controlled by project $\Delta_{t}$, which involves net costs from $t_{0}$ to $t^{*}$ and net benefits from $t^{*}$ to the terminal period, $\tau$. The project cash flows are structured in this way, because physical inertia in the climate system causes the externality to respond slowly to costly abatement efforts. It may also be that climate change is initially beneficial, which is another reason for net costs from $t_{0}$ to $t^{*}$. Let $c_{t}^{u}$ represent consumption under a 'utopian' counterfactual, in which greenhouse gas emissions are uncontrolled but there are no damages from climate change. This is also often referred to as the 'baseline'. While implausible, many previous cost-benefit analyses of climate change have calibrated the consumption discount rate on path $c_{t}^{u}$ by extrapolating past trends of consumption growth without accounting for either the cost of climate change or the cost of emissions reductions. These three consumption pathways are represented in Figure 2.

\section{[Insert Figure 2 (three consumption pathways in theory) about here.]}

We want to examine the circumstances in which DCF analysis may give a misleading evaluation of the welfare consequences of the project to control carbon emissions. Suppose the project is non-marginal, such that the stream of cash flows $\Delta_{t}$ is large (as in Figure 2). Then the difference between business-asusual consumption and consumption if the project is undertaken will be large. Welfare analysis based on proposition 1 (the first-order Taylor approximation) may be unreliable because it applies to a set of consumption discount factors along a particular path (be it $c_{t}^{b}, c_{t}^{b}+\Delta_{t}$, or $c_{t}^{u}$ ), even though the project itself shifts the path.

Instead we must go back to the underlying welfare model and measure the difference between social welfare on the path corresponding to the investment in emissions reductions $c_{t}^{b}+\Delta_{t}$ and social welfare on the business-as-usual path $c_{t}^{b}$. Eq. (9) provides a measure of the true welfare increase of the project $\Delta V$, which can be rearranged for $\pi$ and also $\Pi=n_{0} \pi$, which denotes the true aggregate net present (consumption) benefit from the project, given by:

$$
\Pi=n_{0}\left[u^{-1}\left(\frac{\Delta V}{n_{0}}+u\left(c_{0}\right)\right)-c_{0}\right]
$$


Eq. (4) sets out the error in project utility which arises from using the marginal method. An equivalent expression for the error in terms of the net present consumption of the project can be described as follows:

$$
\Omega_{\Pi}=\Pi-\sum_{t=0}^{\tau} \Delta_{t}\left(1+\rho_{t}\right)^{-t}
$$

\subsection{The PAGE model}

To explore whether "serious errors" might be made in the application of CBA to climate change, we use a so-called "integrated assessment model" (IAM) of the linkages between economy and climate. Such models have been used quite extensively over the last two decades, with the ultimate aim of evaluating the welfare effects of planned reductions in greenhouse gas emissions. Amongst the best known studies are those of William Nordhaus, with his DICE model and its variants (Nordhaus, 1994; 2008; Nordhaus and Boyer, 2000). In this study, we use the PAGE model (Hope, 2006), which was also used in the Stern Review (Stern 2007).

While each IAM has idiosyncrasies in terms of its structure, parameterisation and exogenous variables, all models must represent a common set of key relationships. As usual, output is some function of capital and labour and is affected by residual climate damage. Output is consumed or invested, and in a changing climate, it can be specifically invested in both adaptation to climate change and also in emissions abatement, to reduce the amount of residual climate damage:

$$
\begin{array}{r}
Y_{t}=f\left(K_{t}, L_{t}\right)-D_{t} \\
C_{t}=Y_{t}-I_{t}-\Lambda_{t}^{a}-\Lambda_{t}^{e}
\end{array}
$$

where at time $t, Y_{t}$ is output, $K_{t}$ is capital, $L_{t}$ is labour, and $D_{t}$ is residual climate damage. $C_{t}$ is consumption, $I_{t}$ is investment, $\Lambda_{t}^{a}$ is investment in adaptation, and $\Lambda_{t}^{e}$ is investment in emissions abatement.

Output generates emissions of greenhouse gases, which can be reduced by investment in abatement. The flow of emissions to the atmosphere increases the stock of greenhouse gases, subject to the biogeochemical 
cycling of greenhouse gases between the atmosphere, the biosphere, the hydrosphere and the lithosphere:

$$
\begin{array}{r}
E_{t}=e\left(Y_{t}, \Lambda_{t}^{e}\right) \\
G_{t}=g\left(E_{t}, G_{t-1}\right)
\end{array}
$$

where $E_{t}$ is the flow of emissions at time $t$, which is a function $e($.$) of output and investment in emissions$ abatement. The stock of greenhouse gases $G_{t}$ accumulates according to the function $g($.$) , which represents$ the biogeochemical cycling of greenhouse gases.

The increasing atmospheric stock of greenhouse gases changes the Earth's radiation balance and this in turn produces warming. Finally, this warming, which corresponds to an index of changes in a number of climatic variables including temperature, as well as precipitation and sea level, has welfare effects, assuming some degree of adaptation (e.g. it often proves efficient to enhance coastal flood protection instead of simply enduring flooding).

$$
\begin{gathered}
W_{t}=w\left(G_{t}\right) \\
D_{t}=d\left(W_{t}, \Lambda_{t}^{a}\right)
\end{gathered}
$$

where $W$ is warming.

The objective function is generally a social welfare function of the utilitarian type, where welfare $V=n_{0} \sum_{t=0}^{\tau} \beta_{t} u\left(c_{t}\right)$ as applied in Eq. (8) above, except that the PAGE model introduces regional disaggregation and risk (see Eq. (25) in the Appendix), so that social welfare is additive over regional populations and probability-weighted states of nature. Utility per capita is an isoelastic function of consumption per capita, so the elasticity of marginal utility of consumption, $\eta$, now characterises not only intertemporal inequality aversion but also relative risk aversion and spatial inequality aversion.

For our present purposes, PAGE has two advantages. First, it is a stochastic model. By means of stochastic parameters, a Monte Carlo simulation is performed to generate a probability distribution of consumption paths. It is more difficult to run a Monte Carlo simulation in most other IAMs. Second, each of its stochastic parameters is calibrated on the full range of estimates available in the relevant literature. This enables us to include low-probability, extreme outcomes, which recent research in the economics of climate change has shown to be important (Weitzman, 2009). In spanning the literature, 
PAGE is essentially a meta-model and it can thus provide a good approximation to the results of a range of other models. For example, the mean estimate of the marginal damage cost of $\mathrm{CO}_{2}$ made by Hope (2006) with PAGE is close to the central estimate from a range of peer-reviewed IAM studies in Tol's (2005) meta-analysis. In common with most IAM applications, we avoid setting out every one of PAGE's 53 equations for the sake of brevity. However the Appendix details some of the more important parts of the model from an economic point of view, and their relation to the general model set out above. PAGE is described in full in Hope (2006) and unless otherwise stated no changes have been made.

The mitigation project we consider reduces emissions of $\mathrm{CO}_{2}$ with the aim of stabilising the atmospheric stock of $\mathrm{CO}_{2}$ at 550 parts per million (ppm). Stabilising the stock of $\mathrm{CO}_{2}$ at $550 \mathrm{ppm}$ has been a focus for international political and scientific discussions on climate change, featuring prominently in, for instance, the Fourth Assessment Report of the Intergovernmental Panel on Climate Change (IPCC, 2007).

\section{Results}

We begin by plotting the global consumption paths $c_{t}^{b}, c_{t}^{b}+\Delta_{t}$ and $c_{t}^{u}$, estimated by the PAGE model, in Figure 3. The mean paths of $c_{t}^{b}$ and $c_{t}^{b}+\Delta_{t}$ are plotted, while in PAGE $c_{t}^{u}$ is deterministic. Consumption grows in all three scenarios, but the costs and benefits of climate change and the cost of emissions reductions drive a wedge between them, especially towards the end of the modelling horizon. The stream of cash flows from the mitigation investment is negative until after 2100. The consumption deficit brought about by the project reaches its relative peak in 2040 , when it is around $\$ 800$ per capita, or around $-8 \%$ of business-as-usual consumption per capita. This deficit is due not only to the costs of reducing emissions, but also to foregone benefits of initial climate change. ${ }^{4}$ These foregone benefits are evident in the fact that $c_{t}^{b}$ lies fractionally above $c_{t}^{u}$ during this period. However, they disappear after 2080 as the aggregate impacts of climate change turn negative, and $c_{t}^{b}$ lies well below $c_{t}^{u}$ by 2200 . Accordingly, the project cash flow is positive towards the end of the modelling horizon, peaking at around $\$ 6,000$ per capita in 2200 , or around $6 \%$ of business-as-usual consumption.

\footnotetext{
${ }^{4}$ For example, driven by gains in agricultural productivity and health at high latitudes (Mendelsohn et al., 1994; Tol, 2002).
} 


\section{[Insert Figure 3 (cash flows) about here.]}

Since expected NPV (ENPV) will depend on benefits and costs in all states of nature, not just mean benefits and costs, Figure 4 plots the $90 \%$ confidence interval of cash flows as well as the mean cash flow from the project, expressed in terms of a percentage change in consumption per capita relative to $c_{t}^{b}$. As explained above, the mean cash flow is initially negative and peaks at about $-8 \%$ of business-as-usual consumption per capita, turning positive after 2100 and rising to $6 \%$ by 2200 . The fifth percentile cash flow is negative for almost the whole modeling horizon, also peaking at around $-8 \%$ in 2040 . However, the 95 th percentile cash flow, while initially negative, is large and positive in the 22nd century, reaching almost $20 \%$ of business-as-usual consumption by 2200 .

\section{[Insert Figure 4 (90\% confidence intervals) about here.]}

Figures 5(a) and 5(b) plot estimates from PAGE of the ENPV of the mitigation project as a function of the curvature of the isoelastic utility function, $\eta$. These are our central results. In each figure, four sets of estimates are shown, including three estimates of the DCF of the project, with the consumption discount rate in each set calibrated on growth along one of the three paths outlined above (i.e. $c_{t}^{b}, c_{t}^{b}+\Delta_{t}$ and $c_{t}^{u}$ ). The fourth set is our estimate of the true ENPV of the project, which is the change in social welfare due to the project, normalised to present consumption ( $\Pi$ in Eq. (17)).

Figure 5 reports results where $\delta=1$. Panel (a) shows the full range of estimates. As we would expect, there is no difference between DCF and true ENPV - no error - when $\eta=0$. However, as $\eta$ increases from zero, the error $\Omega_{\Pi}$ (see Eq. (18)) increases, because the three DCF estimates fall faster than true ENPV does. Thus DCF analysis generates a substantial quantitative error for small positive values of $\eta$, although it does give the correct signal qualitatively.

For still larger values of $\eta, \Omega_{\Pi}$ is small in absolute terms, in particular too small to discern in panel (a). However, panel (b), which zooms in to show differences when all of the estimates of ENPV are small, shows that, for higher values of $\eta$, it is possible to be qualitatively wrong about the value of the project based on DCF analysis. When $\eta=2$, true ENPV is $-\$ 0.2$ trillion, whereas all estimates of the project DCF are positive. The project passes CBA when in fact welfare is reduced. Indeed, discounting along 
the business-as-usual path $c_{t}^{b}$, the DCF is positive for $\eta<5$, even though true ENPV is negative in this range. ${ }^{5}$

\section{[Insert Figure 5 (ENPV as a function of $\eta$ ) for $\delta=1$ about here.]}

Figure 6 reports results where $\delta=0$. In this case, the true ENPV of the project increases rapidly in the range $0<\eta \leq 0.9$, while the three DCF estimates fall rapidly, thereby generating a very large quantitative error. As $\eta$ increases beyond unity, the true ENPV of the project falls rapidly, reducing the error brought about by estimating DCF. By the time $\eta \approx 1.5, \Omega$ is small in absolute terms. We find that the peak in ENPV is caused by population growth, as explained in section $2 .{ }^{6}$

Panel (b) again zooms in and shows that, for higher values of $\eta$, DCF analysis can give the wrong qualitative signal of the value of the project. When $\eta>3$, a DCF along the paths $c_{t}^{u}$ and $c_{t}^{b}+\Delta_{t}$, yields a negative result, even though true ENPV is positive. The project fails, when in fact welfare is increased. Discounting along the business-as-usual path $c_{t}^{b}$, the project DCF is positive for $\eta<5$, so it gives the correct signal qualitatively, although it is in relative terms a large overestimate of true ENPV. ${ }^{7}$

\section{[Insert Figure 6 (ENPV as a function of $\eta$ ) for $\delta=0$ about here.]}

\section{Conclusion}

This paper has examined the theory and empirics of non-marginal CBA. After defining non-marginality in terms of the inappropriateness of applying a first-order Taylor approximation, theoretical expressions

\footnotetext{
${ }^{5}$ The DCF along $c_{t}^{b}$ declines less rapidly than its counterparts and remains higher, because, in one of the PAGE model runs, consumption in Latin America is lower in 2200 than it is in the initial period, so that increases in $\eta$ actually increase the year-2200 discount factor in this region in this state of nature. In fact, when $\eta>5$ the DCF along $c_{t}^{b}$ begins to rise again, and as $\eta \rightarrow \infty$ so does the DCF (data available from the authors on request).

${ }^{6}$ In principle, ENPV could increase in PAGE as $\eta$ increases, even if population is constant, because the model incorporates regional disaggregation and risk. However, tests with population forced constant at its initial value show that ENPV falls monotically with rising $\eta$ (data available from the authors on request).

${ }^{7}$ The explanation lies, as above, in the single model run that estimates lower consumption in Latin America in 2200 than in 2000 .
} 
for the error in welfare analysis (in utility and consumption terms) were developed. The curvature in the utility function (the elasticity of marginal utility, $\eta$ ) is the source of the error, so the errors are very small for extremely low $\eta$, or extremely high $\eta$. However, extreme values of $\eta$ are not well supported by the empirical evidence, and more serious errors are theoretically possible for non-marginal projects evaluated with intermediate $\eta$, for which there is good evidence. Further, non-marginality creates the possibility of some unusual counterintuitive results when projects are evaluated in the context of a growing population. This paper found the conditions under which an increase in $\eta$ can increase project NPV, in a setting without risk or distributional considerations.

The empirical part of the paper employed the PAGE integrated assessment model of climate change, used by Stern (2007), to investigate whether conventional CBA of globally coordinated reductions in greenhouse gas emissions could yield significant quantitative errors, or, perhaps even worse, suggest outcomes which were qualitatively wrong. Both qualitative and large quantitative errors were found to be plausible outcomes from the PAGE model results, depending on $\eta$ and the utility discount rate, $\delta$. It is noted, however, that PAGE was used appropriately by Stern (2007) in dealing with the non-marginal nature of climate change.

Following Dasgupta et al. (1972), we conclude that if there is cause to suspect a project under evaluation is not "small", in the sense that the range of net benefits might be a significant share of aggregate consumption, then the ENPV rule will not suffice. Instead, analysts must fall back on a general equilibrium model, which is capable of evaluating the underlying change in social welfare brought about by the project. This has important implications for the evaluation of large development projects in small economies, as well as the evaluation of the costs and benefits of climate change mitigation. 


\section{Appendix: The PAGE model}

PAGE is a stochastic IAM with eight world regions and a time horizon of two hundred years, from 2000 to 2200 . Expected social welfare is the sum of utility per capita across regions $j=1 \ldots 8$, weighted by their populations, time periods, weighted by the utility discount rate, and states of nature $i$, weighted by their probabilities $p_{i}$ :

$$
E(V)=\sum_{j=1}^{8} \sum_{t=0}^{200} \sum_{i} p_{i} u\left(c_{i, j, t}\right) n_{j, 0}\left(1+g_{j, t}\right)^{t}(1+\delta)^{-t}
$$

Utility per capita is an isoelastic function of consumption per capita, $u\left(c_{i, j, t}\right)=c_{i, j, t}^{1-\eta} /(1-\eta)$, where $\eta$ is the elasticity of the marginal utility of consumption, which simultaneously captures aversion to inequality in consumption over regions and time, and relative risk aversion.

In PAGE, output, population and the savings rate are exogenous. This conserves modelling resources, which are devoted to Monte Carlo simulation. Consumption in a changing climate is thus given by baseline output, converted to consumption using an exogenous savings rate, less investment in adapting to climate change and in emissions abatement, and less residual climate damage:

$$
C_{i, j, t}=s \hat{Y}_{i, j, t}-\Lambda_{i, j, t}^{a}-\Lambda_{i, j, t}^{e}-D_{i, j, t}
$$

where $s$ is the savings rate, which we set to $20 \%$, and $\hat{Y}$ is baseline output, and where $\hat{Y}, n, g$, and consistent greenhouse gas emissions are taken from the popular Common Poles Image scenario of den Elzen et al. (2003), extrapolated from 2100 to 2200 by Alberth and Hope (2007). Annual emissions of $\mathrm{CO}_{2}$ in the Common Poles Image scenario are around 38 gigatonnes (Gt) in 2010, peaking at around 57 Gt in 2060 and are constant at around 51 Gt from 2100 to 2200. We also consider a scenario in which $\mathrm{CO}_{2}$ emissions are abated with the aim of stabilising the atmospheric stock of $\mathrm{CO}_{2}$ at 550 parts per million (ppm). $\mathrm{CO}_{2}$ emissions are thus the product of baseline emissions and the emissions control rate:

$$
E_{i, j, t}=\gamma_{j, t} \hat{E}_{i, j, t}
$$

where $\gamma_{j, t}$ is the emissions control rate and $\hat{E}$ denotes baseline emissions.

Investment in emissions abatement is given by a two-step function, in which emissions up to some maximum share of baseline emissions can be abated at a low cost, whereas emissions beyond that maximum 
are abated at a higher cost:

$$
\Lambda_{i, j, t}^{e}=\left\{\begin{array}{cc}
\theta_{i, j} \gamma_{j, t} & \gamma \leq \bar{\gamma} \\
\tilde{\theta}_{i, j}\left(\gamma_{j, t}-\bar{\gamma}_{j, t}\right) & \gamma>\bar{\gamma}
\end{array}\right.
$$

where $\bar{\gamma}$ is the maximum emissions control rate achievable at low cost, $\theta$ is the unit cost of abating emissions up to the maximum, and $\tilde{\theta}$ is the unit cost of abating emissions above the maximum. The equations of the model describing the climatic response to emissions can be found in Hope (2006).

Residual climate damage comes from two sources. The first represents the consequences of what we might call 'gradual' climate change on production, as well as on environmental goods and services that do not have a market price (such as most changes in unmanaged ecosystems). The second represents a 'catastrophic' large-scale change in the climate system such as rapid melting of the Greenland and/or West Antarctic ice sheets.

$$
D_{i, j, t}=\hat{Y}_{j, t}\left(\Psi_{i, j, t}^{g r a d}+\Psi_{i, j, t}^{c a t}\right)
$$

where $\Psi^{\text {grad }}$ is the impact of gradual climate change and $\Psi^{\text {cat }}$ is the impact of catastrophic climate change, both expressed as percentages of output. The cost of gradual climate change is given by:

$$
\Psi_{i, j, t}^{g r a d}=\alpha_{i, j}\left(\frac{W_{i, j, t}-A T L_{j, t}}{2.5}\right)^{\beta} \kappa_{j, t}
$$

Where $\alpha$ sets the region-specific cost of $2.5^{\circ} \mathrm{C}$ warming, $\beta$ is the damage-function exponent, and $A T L$ is the tolerable level of warming before damage occurs. Adaptation reduces the gradual cost of climate change in two ways. First, it can increase $A T L$. Second, it reduces damage in excess of that tolerable level by the factor $\kappa . A T L$ is itself a function both of the level of warming, $A T P$ and the rate of warming, ATR:

$$
A T L_{j, t}=\min \left(A T P_{j, t}, A T L_{j, t-1}+A T R_{j, t} t\right)
$$

Equation (32) gives the cost of catastrophic climate change:

$$
\Psi_{i, j, t}^{c a t}=P C A T_{i} . L O S S_{i, j}\left(W_{i, t}-\tilde{W}_{i}\right)
$$

Where $P C A T$ is the probability of a catastrophe, LOSS is the loss of output if a catastrophe occurs, and $\tilde{W}$ is the threshold global mean temperature, above which a catastrophe becomes possible. It is assumed that the costs of such a catastrophe cannot be reduced by adaptation. 
The cost of adaptation is the sum of the cost of raising the tolerable rate and level of warming before damages begin, and the cost of adapting to residual damages:

$$
\Lambda_{i, j, t}^{a}=\phi_{i, j, t}^{A T P} A T P_{i, j, t}+\phi_{i, j, t}^{A T R} A T R_{i, j, t}+\phi_{i, j, t}^{\kappa} \kappa_{j, t}
$$

where the vector $\phi$ contains the exogenous adaptive cost parameters corresponding to each method of adaptation. 
[1] Atkinson, A.B. (1970). 'On the measurement of inequality', Journal of Economic Theory vol. 2, pp. 244-263.

[2] Atkinson A.B., Brandolini, A. (2009). 'On analysing the world distribution of income', Temi di Discussione (Economic working papers) 701, Bank of Italy, Economic Research Department.

[3] Byatt, I., Castles, I., Goklany, I.M., Henderson, D., Lawson, N., McKitrick, R., Morris, J., Peacock, A., Robinson, C., and Skidelsky, R., 2006. 'The Stern Review: a dual critique. Part II: Economic aspects', World Economics, vol. 7(4), pp. 195-229.

[4] Dasgupta, P., Marglin, S., and Sen, A. (1972). Guidelines for Project Evaluation, New York: UNIDO.

[5] Dasgupta, P. (2007). 'Commentary: The Stern Review's economics of climate change', National Institute Economic Review vol. 199, pp. 4-7.

[6] Drèze, J., Stern, N., (1987). 'The theory of cost-benefit analysis', in: Auerbach, A. and Feldstein, M. (Eds.), Handbook of Public Economics, Vol. II, Amsterdam: North-Holland, pp. 909-89.

[7] Hahn, R.W., Tetlock, P.C. (2008). 'Has economic analysis improved regulatory decisions?', Journal of Economic Perspectives vol. 22(1), pp. 6784.

[8] Hammond, P.J. (1990). 'Theoretical progress in public economics: a provocative assessment', Oxford Economic Papers vol. 42(1), pp. 6-33.

[9] Hope, C. (2006). 'The marginal impact of $\mathrm{CO}_{2}$ from PAGE2002: an integrated assessment model incorporating the IPCC's five reasons for concern', Integrated Assessment vol. 6(1), pp. 19-56.

[10] IPCC (2007). Climate Change 2007: Synthesis Report. Geneva: IPCC.

[11] Johansson-Stenman, O., Carlsson, F., Daruvala, D. (2002). 'Measuring future grandparents' preferences for equality and relative standing', ECONOMIC Journal, vol. 112, pp. 362-383.

[12] Kelly, D.L., Kolstad, C.D. (1999). 'Integrated assessment models for climate change control', in: Folmer, H. and Tietenberg, T. (Eds.), International Yearbook of Environmental and Resource Economics 1999/2000: A Survey of Current Issues. Cheltenham, UK: Edward Elgar. 
[13] Layard, R., Mayraz, G., Nickell, S. (2008). 'The marginal utility of income', Journal of Public Economics vol. 92(8-9), pp. 1846-1857.

[14] Little I.M.D., Mirrlees J.A. (1974). Project Appraisal and Planning for Developing Countries, London: Heinemann.

[15] Mendelsohn, R.O., Nordhaus, W.D., Shaw, D. (1994). 'The impact of global warming on agriculture: a Ricardian analysis', American Economic Review vol. 84, pp. 753-771.

[16] Mishan, E.J., Quah, E. (2007). Cost-Benefit Analysis. London: Routledge.

[17] Myles, G.D. (1995). Public Economics, Cambridge, UK: Cambridge University Press.

[18] Nordhaus, W.D. (1994). Managing the Global Commons: the Economics of Climate Change. Cambridge, MA: MIT Press.

[19] Nordhaus, W.D. (2008). A Question of Balance: Weighing the Options on Global Warming Policies. New Haven: Yale University Press.

[20] Nordhaus, W.D., Boyer, J. (2000). Warming the World: Economic Models of Global Warming. Cambridge, MA: MIT Press.

[21] Nordhaus W.D. (2007). 'A review of the Stern Review on the Economics of Climate Change', Journal of Economic Literature vol. 45, pp. 686-7.

[22] Pearce, D.W., Atkinson, G., Mourato, S. (2006). Cost-Benefit Analysis and the Environment, Paris: OECD.

[23] Ramsey, F. (1928). 'A mathematical theory of saving', Economic Journal vol. 38, pp. 543-59.

[24] Stern, N. (1977). 'Welfare weights and the elasticity of the marginal valuation of income', in: Artis, M., Nobay, R. (Eds.), Proceedings of the AUTE Edinburgh meeting of April 1976. Basil Blackwell.

[25] Stern, N. (2007). Stern Review: The Economics of Climate Change. Cambridge, UK: Cambridge University Press.

[26] Tol, R.S.J. (2002). 'Estimates of the damage cost of climate change - part II: dynamic estimates', Environmental and Resource Economics vol. 21, pp. 135-160. 
[27] Tol, R.S.J. (2005). 'The marginal damage costs of carbon dioxide emissions: an assessment of the uncertainties', Energy Policy vol. 33(16), pp. 2064-2074.

[28] Weitzman, M.L. (2007). 'A review of the Stern Review on the Economics of Climate Change'. Journal of Economic Literature vol. 45(3), pp. 703-724.

[29] Weitzman, M.L. (2009). 'On modeling and interpreting the economics of catastrophic climate change', Review of Economics and Statistics vol. 91(1), pp. 1-19.

[30] World Bank and MIGA, (2005). Project Appraisal Document on a Proposed IDA Grant (Nam Theun 2 Social and Environmental Project) in the amount of SDR13.1 million (\$US20 million equivalent) to the Lao People's Democratic Republic and a Proposed IDA Partial Risk Guarantee in the amount of up to US\$50 million for a Syndicated Commercial Loan and Proposed MIGA Guarantees of up to \$US200 million in Lao People's Democratic Republic and Thailand for a Syndicated Commercial Loan to and an Equity Investment in the Nam Theun 2 Power Company Limited for the Nam Theun 2 Hydroelectric Project, Washington DC: World Bank. 


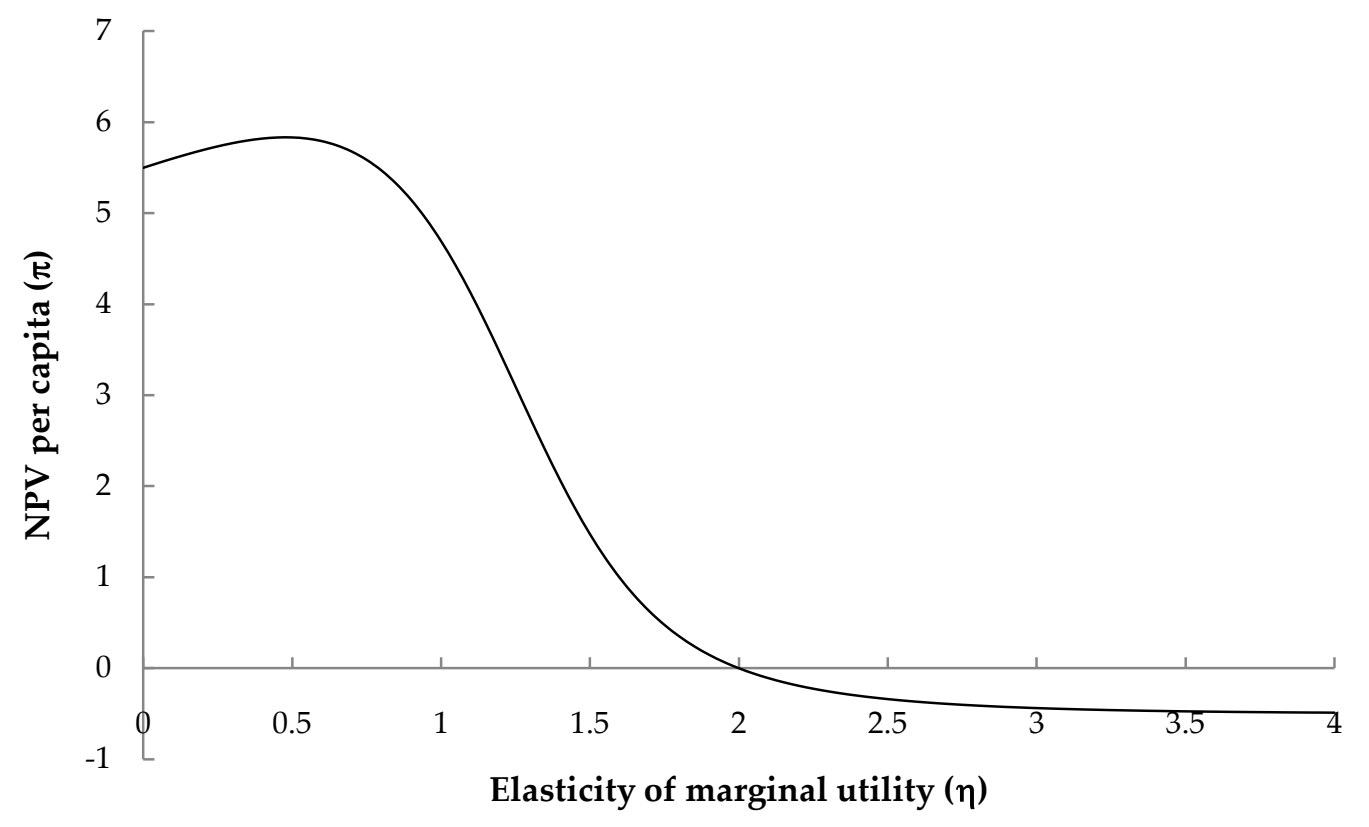

Figure 1: A non-monotonic relationship between $\pi$ and $\eta$ can arise for non-marginal projects with $\beta>1$.

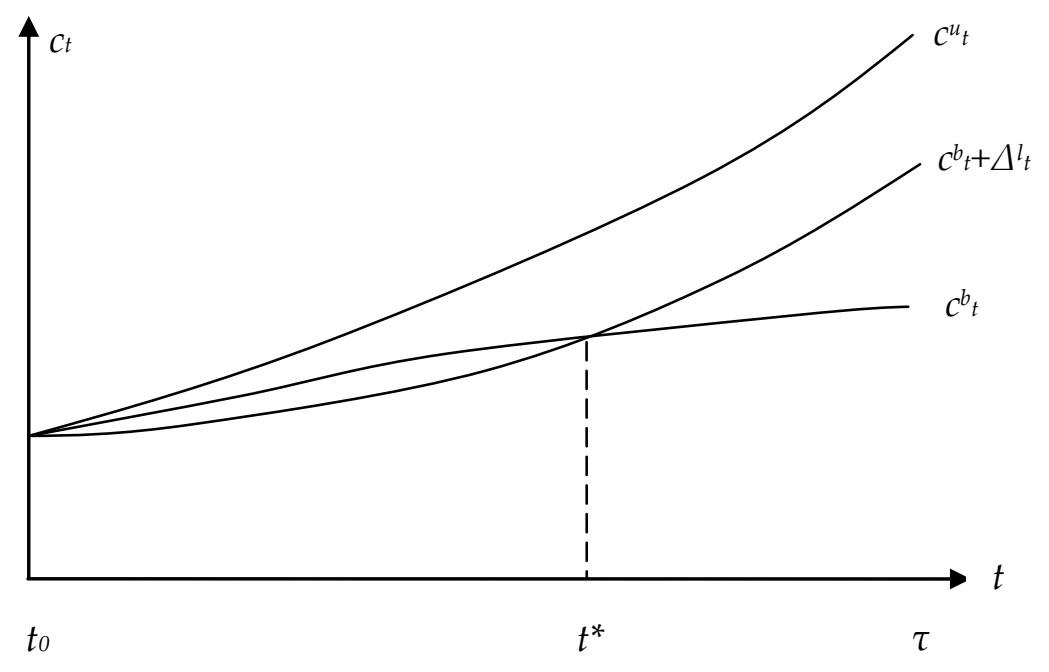

Figure 2: Three theoretical consumption pathways. 


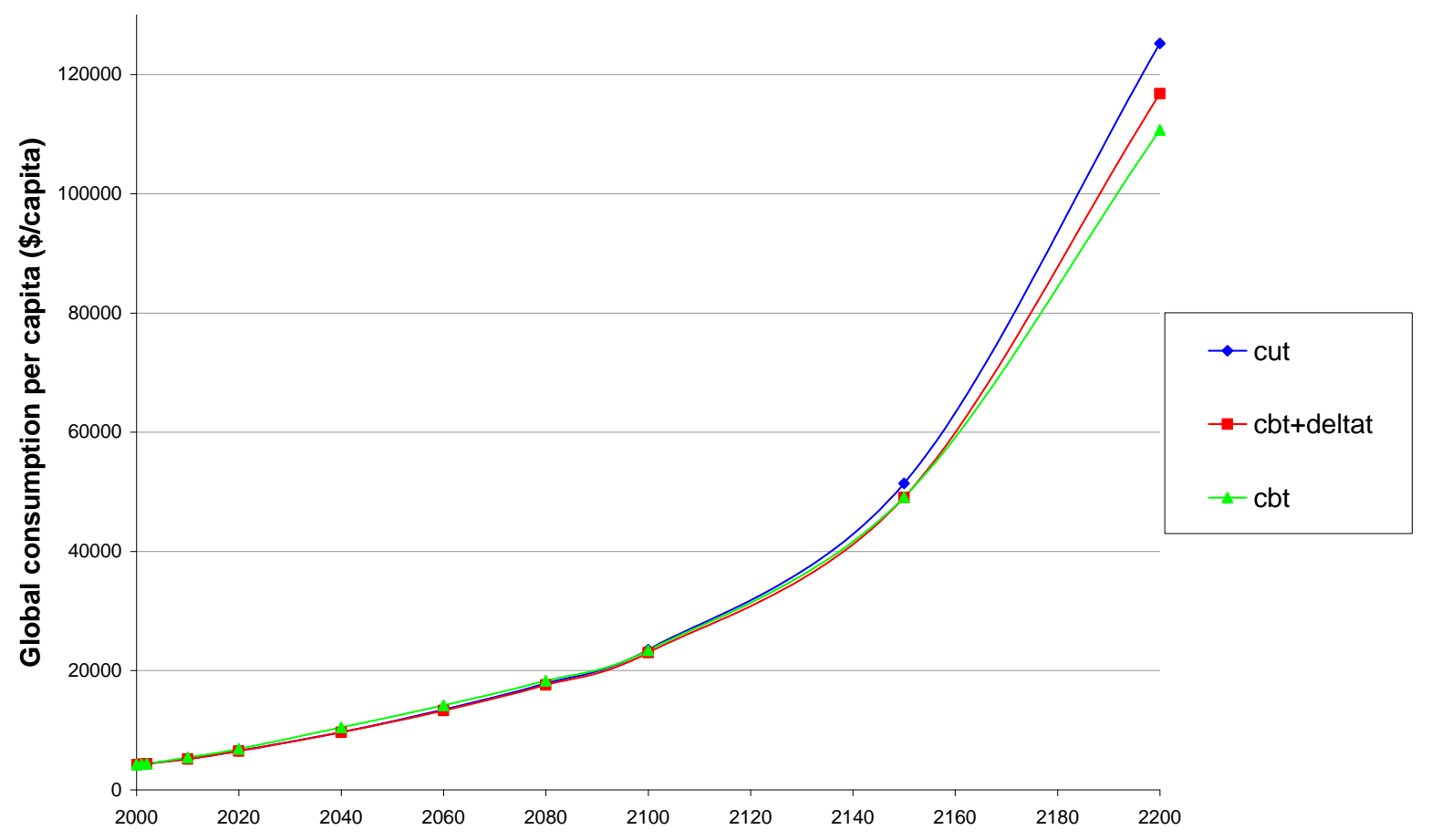

Figure 3: PAGE cash flows. 


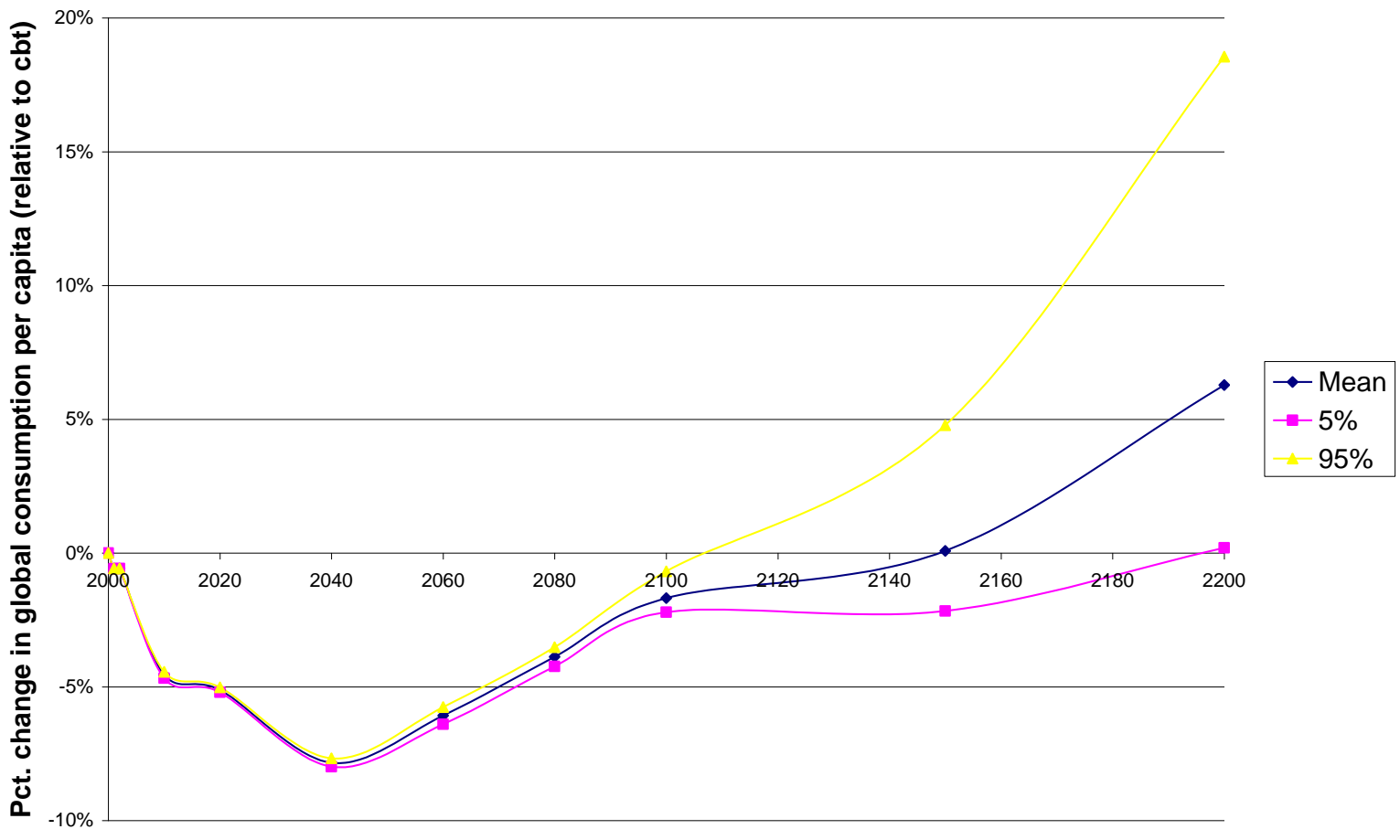

Figure 4: 90\% confidence intervals. 
Panel (a)

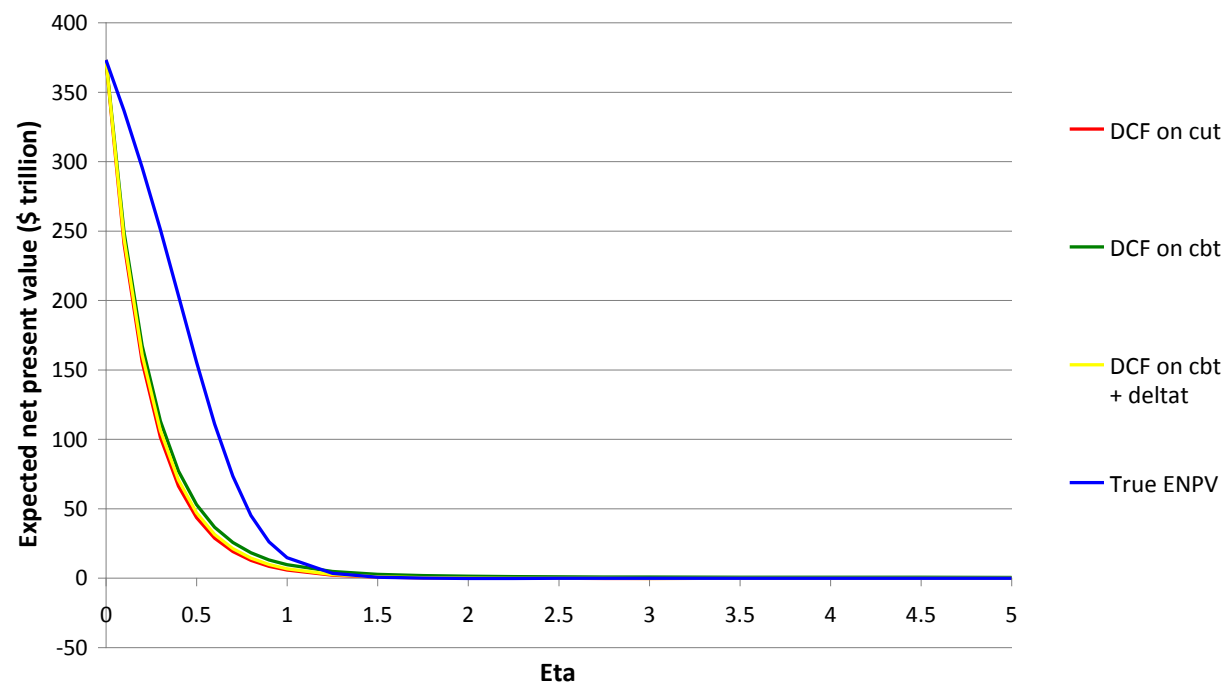

\section{Panel (b)}

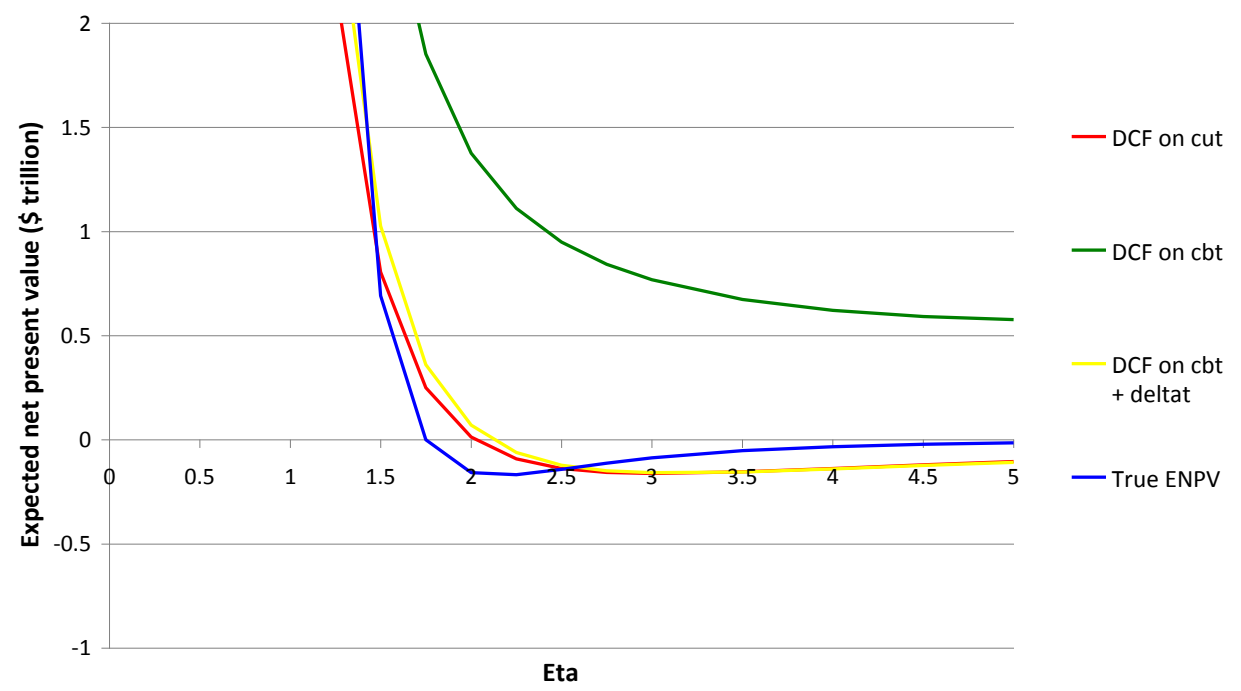

Figure 5: ENPV as a function of $\eta$ for $\delta=1$. 
Panel (a)

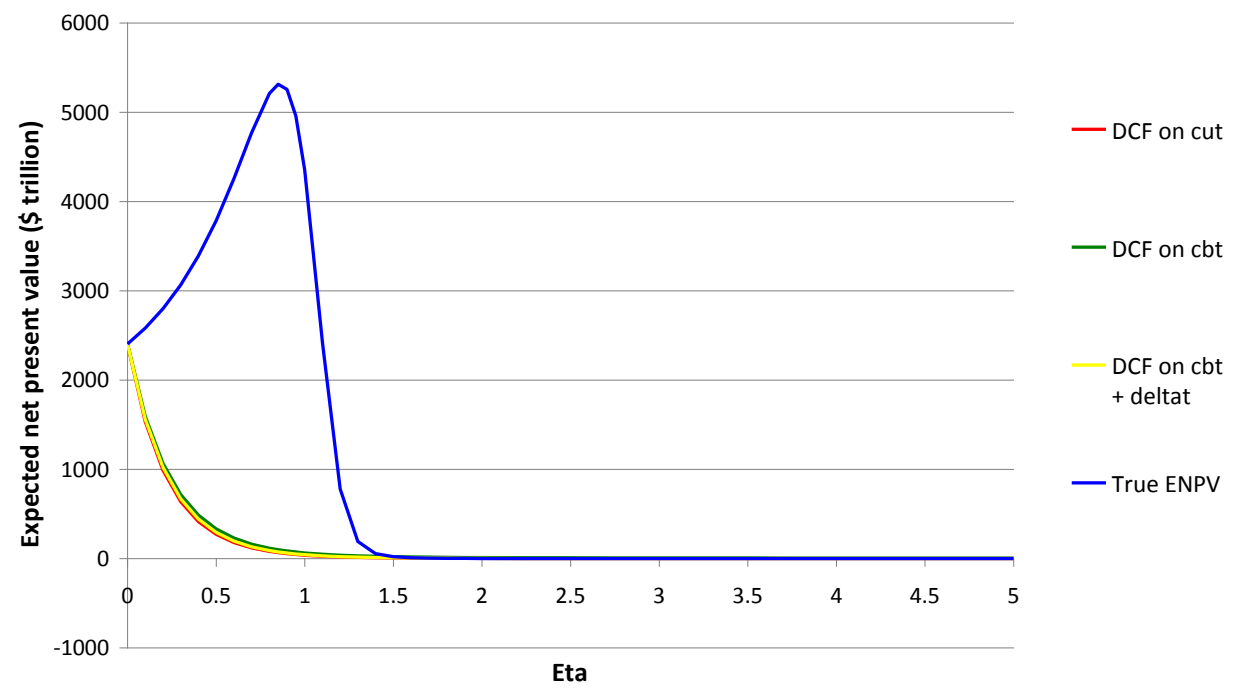

Panel (b)

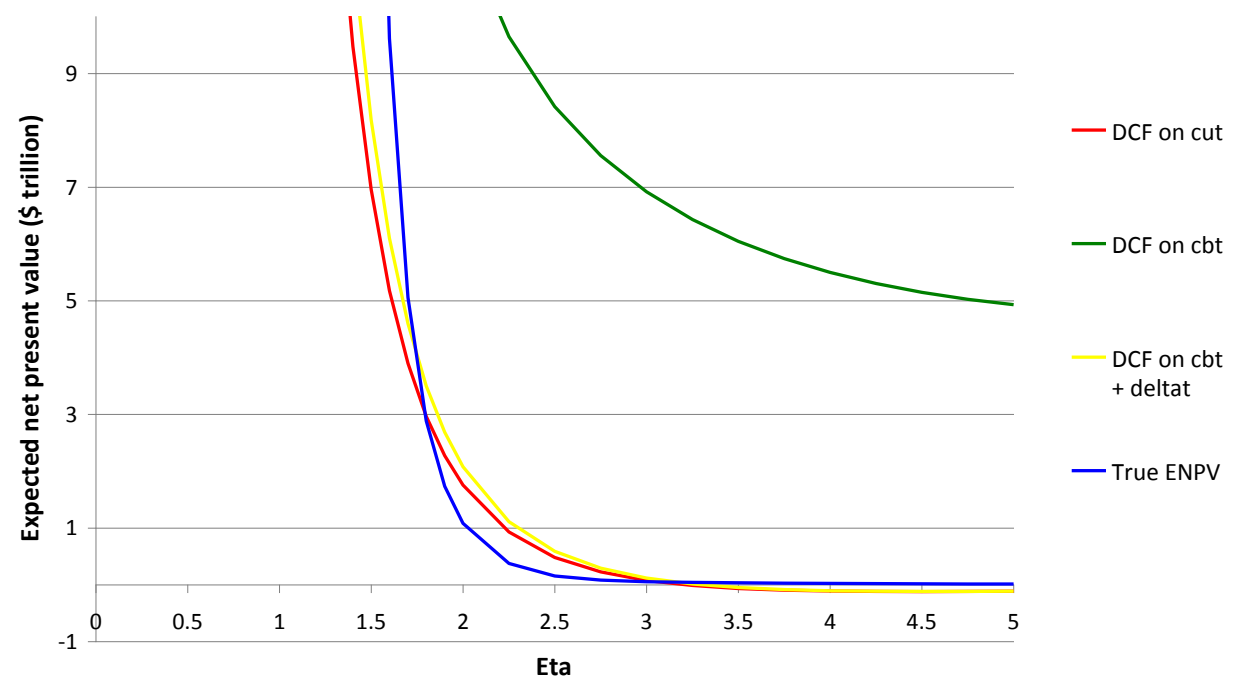

Figure 6: ENPV as a function of $\eta$ for $\delta=0$. 